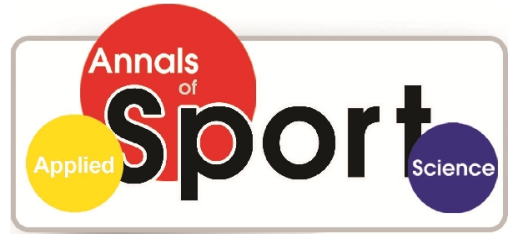

www.aassjournal.com

ISSN (Online): $2322-4479$

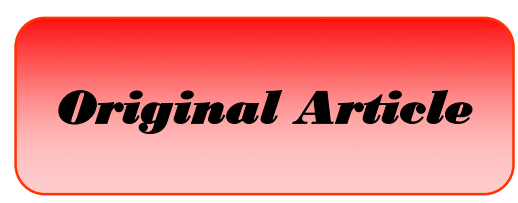

Received: $14 / 09 / 2013$

Accepted: 31/03/2014

\title{
Short-Term Effects of Oral Feeding Jujube Ziziphus Solution before a Single Session of Circuit Resistance Exercise on Apoptosis of Human Neutrophil ${ }^{1}$ Seyed Morteza Tayebi, ${ }^{2}$ Hamid Agha-Alinejad ${ }^{*}$, Shahriar Shafaee, ${ }^{2}$ Reza Gharakhanlou, ${ }^{4}$ Mohsen Asouri
}

1. Faculty of Physical Education and Sport Science, Allameh Tabataba'i University, Tehran, Iran.

2. Department of Physical Education, Faculty of Humanities, Tarbiat Modares University, Tehran, Iran.

3. Department of Pathology, Faculty of Medicine, Babol University of Medical Science, Babol, Iran.

4. North Research Center, Pasteur Institute of Iran, Amol, Iran.

\begin{abstract}
The aim of present research was the effect of short-term use of edible solution of jujube one week before a single session of circuit resistance exercise on neutrophil apoptosis of male students of physical education. 14 young male volunteer students were divided into two groups of placebo ( $\mathrm{n}=7$, aged 24.50 \pm 2.50 , height $171.17 \pm 1.70$, and weight $67.51 \pm 4.92)$ and jujube solution ( $\mathrm{n}=7$, aged $25.25 \pm 1.31$, height $179.75 \pm 3.63$, weight $74.07 \pm 5.78$ ) at random, performing one circuit resistance exercise ( 9 moves/stops, 30 seconds for each exercise, 3 nonstop sets with a 3-minute active recession between sets, 10-14 repetitions, and an intensity of 70\% maximum repetition). Subjects received placebo and jujube solutions $\left(0.5 \mathrm{~g} / \mathrm{kg}_{\text {body weight }}\right.$ in $2.5^{\mathrm{cc}}$ of distilled water as long as 7 days $)$ at certain times and double-blind. Blood samples were collected 30 minutes before, immediately, and 2 hours after the exercise for separation and counting the number of neutrophils, and neutrophil apoptosis was determined through AnexinV-FITC kit and flow cytometric method. The results indicated the significant response of initial apoptosis neutrophils to one course of activity by jujube group. However, different responses were observed between two groups of placebo and jujube during the recession after training. Unlike placebo group, the response was significantly lower with a greater decrease after training in jujube group. However, necrosis/delayed apoptosis neutrophils significantly increased in placebo group after 2 hours, while this change was not observed in jujube group. At the end of a 2-hour recession, delayed apoptosis neutrophils significantly decreased in both placebo and jujube groups. The present findings indicate that one-session resistance activity is not very effective after pretreatment with jujube solution during one week. Perhaps this useful effect of jujube can be explained by existing glucose compounds and amino acids which could provide neutrophils with proper nutrition source in comparison with placebo. It is possible that jujube resulted in improvement of neutrophil's antioxidant capacity, because it has proper antioxidant materials. Therefore, it might be stated that loading with edible jujube solution can be effective in inhibiting apoptosis at least for one week.
\end{abstract}

Key Words: Oral Jujube Solution, Neutrophil, Early Apoptotic, Late Apoptosis, Necrotic Neutrophils.

Corresponding Author:

Hamid Agha-Alinejad

E-mail: halinejad@modares.ac.ir 


\section{INTRODUCTION}

Neutrophils play a critical role in the first line of defense against pathogens. They rapidly migrate to the infection site, ingest the pathogens, release reactive oxygen species (ROS) to kill the pathogens, and even release their own DNA to form extracellular traps (1).

It is important that neutrophil activity be tightly regulated to prevent perpetuation of inflammation (2). Despite having a life span of 5 days under physiological conditions (3), neutrophil longevity is extended in inflammatory environments by delaying apoptosis/programmed cell death. Nevertheless, once an episode of acute neutrophilic inflammation is complete, it is essential that neutrophil recruitment be halted and that recruited neutrophils undergo apoptosis, before disposal of the apoptotic cells by surrounding phagocytes such as macrophages, to ensure efficient resolution of inflammation (4).

The natural process of neutrophil apoptosis resolution followed by phagocytosis is impaired in numerous human inflammatory disease states with delayed apoptosis (5-8) seen in exercise conditions (9). Recently, Mooren et al. (2012) reported that neutrophil apoptosis was delayed after both marathon run and intensive laboratory exercise tests evaluated with annexin $\mathrm{V}$ labeling and flow cytometry measuring. Apoptosis delay was accompanied under these exercise conditions by enhanced intracellular calcium transients and decreased glutathione levels. However, previous human studies show that repeated acute exercise increases apoptosis and reduces mitochondrial membrane potential $(\Delta \Psi \mathrm{m})$ in neutrophils (10-12).

Besides, a single bout of exercise induces an inflammatory response that is similar to that brought about by infection or trauma (13). A prolonged inflammatory state has detrimental health effects and predisposes to a number of chronic diseases and health conditions (13).

The control of granulocyte cell death and subsequent clearance of the apoptotic cell is not only crucial for maintaining homeostasis, but also paramount to an efficient resolution of inflammation (14). Neutrophils undergo spontaneous apoptosis at inflamed sites (15).

There are contradictory and limited reports about effect of glutamine supplementation in acute exercise and neutrophil response to it; it is reported in a review article that glutamine supplementation is beneficial for immunological function only in clinical situations and it wasn't proven that it is effective for prevention of immune cells function following exercise $(16,17)$; so that, the effect of glutamine supplementation wasn't significant during and after exercise (18). But some reports said that glutamine supplementation had an either significant effect on neutrophil function due to exercise (19) or a protective effect on neutrophil apoptosis due to acute exercise $(20,21)$, and also, an study without exercise intervention reported a protective effect against events with stimulation and execution of apoptosis on human and rat neutrophil (22).

Recently, herbal medicine and medical plants are widely used for the treatment of diseases and weight management $(23,24)$. Zizyphus/Jujube/Red Date/Annab is a plant of Khamancea family that contains different kinds of proteins, sugars, and also amino acids such as alanine, aspartic acid, glutamic acid (25), can participate in glutamine formation. Ghanbari-Niaki et al. (2013) investigated the effect of aerobic training, with or without Zizyphus Jujuba water extraction, on fundus nesfatin-1, ATP, HDLc, and LDL-c concentrations (26) and liver and plasma Nesfatin-1 (27) in female rats and concluded that exercise and using jujube extraction may prevent over-weight and 
cardiovascular diseases (26) and it could be considered as an anti-appetite herb (27).

It is believed the dried fruits of Zyzyphus jujube are anodyne, anticancer, pectoral, refrigerant, sedative, stomachic, styptic and tonic and immune response enhancer (28$30)$. It has anti-inflammatory and antidiabetic effects (26).

However, there are studies about beneficial effect of jujube extraction and some it's compounds on immunological function (31-35) and also it is presented about protective effects of it on oxidant status (36-38), but there are a few studies about effects of jujube extraction on apoptosis induction in tumor cells $(39,40)$ and an report exist about the effects of jujube extraction on apoptosis status in heart muscles in response to acute exercise (41), but there isn't any evidence about neutrophil specially.

So, the main question of this study is what the short-term effects of oral feeding Ziziphus Jujube solution is before a single session of circuit resistance exercise on apoptosis of human neutrophil cells measuring with Anexin V labeling and flow cytometry method.

\section{MATERIALS AND METHODS}

Subjects. The present study was approved by the Research Ethics Committee of the School of Medical Sciences of Tarbiat Modares University (Iran), and conducted in accordance with policy statement of the Declaration of Iranian Ministry of Health. Written informed consent was obtained from 14 young healthy male students. All subjects were asked to complete a medical examination as well as a medical questionnaire to ensure that they were not taking any regular medications for 1 month ago; no smoking, no alcohol, no regular exercise in the past 2 months, and free of cardiovascular or metabolic diseases, and also, recent symptoms of upper respiratory tract infection in 1 month before beginning the test. The volunteers were assigned randomly to 2 groups $(n=7)$ including a Circuit Resistance Exercise group with placebo (CREP) (age: 24.5 \pm 2.5 years, height: $171.17 \pm 1.7 \mathrm{~cm}$, weight: $67.51 \pm 4.92$ $\mathrm{kg}$ ) and Circuit Resistance Exercise group $(n=7)$ with jujube solution (age: $25.25 \pm 1.31$ years, height: $179.75 \pm 3.63 \mathrm{~cm}$, weight: $74.04 \pm 5.78 \mathrm{~kg})$ (CRES).

Exercise Protocol and Blood Collection. Participants were taken to the weight room three times before the main trial. Strength test was performed on the first and second visits to determine one repetition maximum (1-RM) of all the participants for each of the 9-resistance exercises, employed in the study. The 1-RM value was determined by trial and by adding or removing weights after each attempt as per required. The subjects were allowed to take as long time as they felt necessary to recover from each attempt. The subjects completed a practice session to ensure that each participant was able to complete the entire exercise session on the third visit, and also to confirm that the weight lifting was producing fatigue at the end of the session. This was confirmed by visual and verbal feedback from the participants (42). Records of 1-RM are presented in table 1.

Subjects in both groups arrived in the place of test at 08:00 and rested for about 30 minutes, all subjects performed the circuit resistance exercise in two circles at 08:30 at the same time. Each circle contained 9 exercises (crunch, back extension, biceps curl, triceps press, knee extension, knee curl, standing calf raise, chest press, seated row, all with machines). The test included three non-stop circuits with 3-minute active rests between circuits. Each exercise performed $30 \mathrm{~s}$ (about $10-14$ repeats) with $75 \%$ one repeat maximum (1RM). The exercise protocol is drawn in figure 1. 
Table 1. Exercise's 1-RM Records of participants

\begin{tabular}{|c|c|c|c|}
\hline & Variables $(\mathrm{kg})$ & groups & Mean \pm SE \\
\hline \multirow{2}{*}{1} & \multirow{2}{*}{ crunch } & placebo & $127.12 \pm 8.66$ \\
\hline & & Jujube solution & $129.49 \pm 10.21$ \\
\hline \multirow{2}{*}{2} & \multirow{2}{*}{ back extension } & placebo & $199.76 \pm 24.46$ \\
\hline & & Jujube solution & $270.77 \pm 82.12$ \\
\hline \multirow{2}{*}{3} & \multirow{2}{*}{ biceps curl } & placebo & $54.01 \pm 5.38$ \\
\hline & & Jujube solution & $62.55 \pm 4.49$ \\
\hline \multirow{2}{*}{4} & \multirow{2}{*}{ triceps press } & placebo & $57.39 \pm 4.29$ \\
\hline & & Jujube solution & $60.97 \pm 4.67$ \\
\hline \multirow{2}{*}{5} & \multirow{2}{*}{ knee extension } & placebo & $156.15 \pm 13.07$ \\
\hline & & Jujube solution & $173.69 \pm 11.27$ \\
\hline \multirow{2}{*}{6} & \multirow{2}{*}{ knee curl } & placebo & $100.43 \pm 9.67$ \\
\hline & & Jujube solution & $110.35 \pm 18.12$ \\
\hline \multirow{2}{*}{7} & \multirow{2}{*}{ standing calf raise } & placebo & $152.63 \pm 15.20$ \\
\hline & & Jujube solution & $166.08 \pm 10.25$ \\
\hline \multirow{2}{*}{8} & \multirow{2}{*}{ chest press } & placebo & $73.29 \pm 3.38$ \\
\hline & & Jujube solution & $77.56 \pm 9.83$ \\
\hline \multirow{2}{*}{9} & \multirow{2}{*}{ seated row } & placebo & $126.46 \pm 7.73$ \\
\hline & & Jujube solution & $149.15 \pm 11.45$ \\
\hline
\end{tabular}

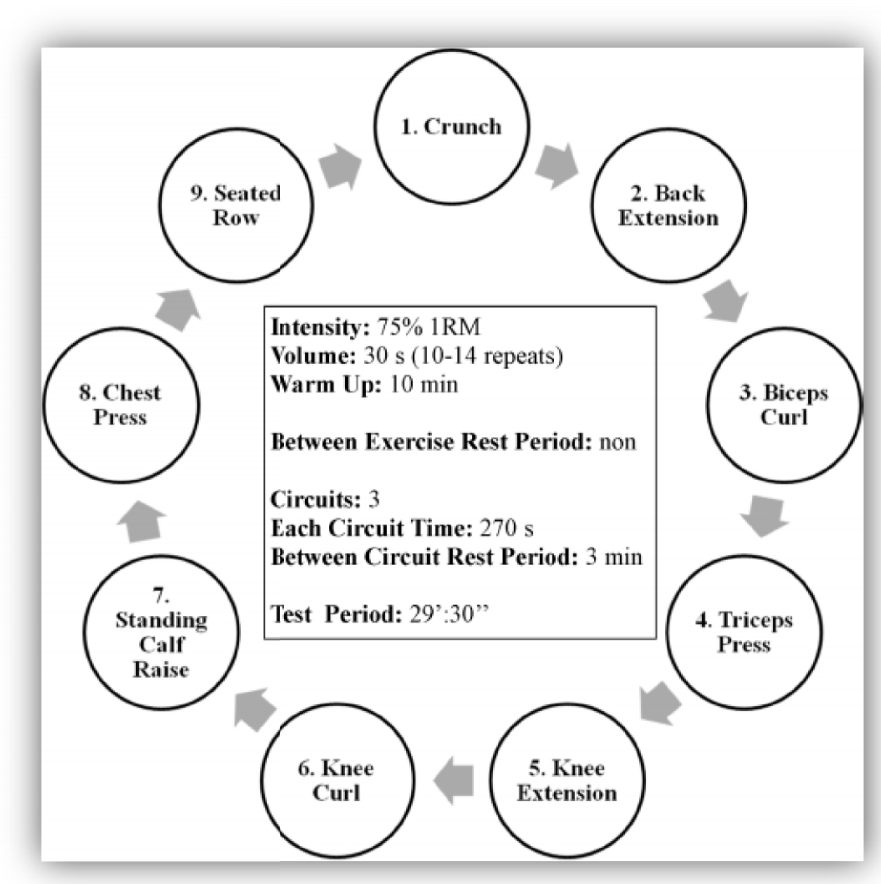

Figure 1. Exercise protocol

The semi-dried fruits of Zyzyphus Jujube were washed, and their seeds were separated and removed from soft red parts. The samples were dried in $50^{\circ} \mathrm{C}$ and were grounded into powder in a mortar. The groups received oral jujube solution (0.5 $\mathrm{g} / \mathrm{kg}$ body weight in $2.5 \mathrm{cc}$ distilled water) and placebo $(2.5 \mathrm{cc} / \mathrm{kg}$ of body weight in distilled water sweetened by sugar without the calories and colored by food dyes) daily 
for one week in double blind manner without any physical training during this period. First, peripheral venous blood samples were drawn $\left(8^{\text {th }}\right.$ day and after 12 hours of overnight fasting) at 08:30. Second, blood samples were taken immediately after exercise at 09:00, then subject sited for 120 minutes. Third, blood samples were drawn at 11:00. The research design and blood collection is drawn in figure 2 .

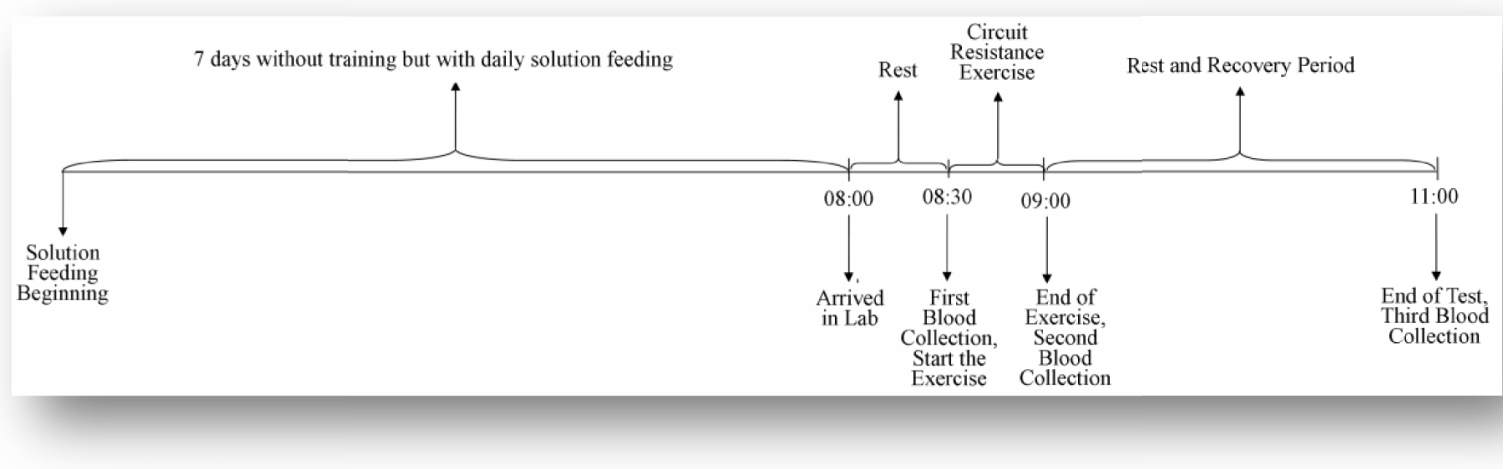

Figure 2. Research Design and Blood Collection

Reagents. Anticoagulant ACD [mixture of citric acid (Sigma Aldrich, Germany), sodium citrate (Sigma Aldrich, Germany), dextrose (Sigma Aldrich, Germany), and Deionized Sterile Distilled Water/ $\mathrm{dsdH}_{2} \mathrm{O}$ (Baharafshan, B.I.R.D, Iran)], Dextran 6\% [combination of dextran with at least 100000 MW (grade B, BDH lab, GPR ${ }^{\mathrm{TM}}$, England), $0.9 \% \mathrm{NaCl}$ (Sigma Aldrich, Germany), and $\mathrm{dsdH}_{2} \mathrm{O}$ ], $0.6 \mathrm{M} \mathrm{KCl}$ [mixture of $\mathrm{KCl}$ (Sigma Aldrich, Germany), and $\mathrm{dsdH}_{2} \mathrm{O}$ ], Phosphate buffered saline/PBS solution [combination of $\mathrm{NaCl}, \mathrm{KCl}, \mathrm{Na}_{2} \mathrm{HPO}_{4}$ (Sigma Aldrich, Germany), $\mathrm{KH}_{2} \mathrm{PO}_{4}$ (Sigma Aldrich, Germany), and $\mathrm{dsdH}_{2} \mathrm{O}$ ] with $\mathrm{pH}$ 7.4 and Autoclaved, Hank's Balanced Salt Solution/HBSS without $\mathrm{Ca} \& \mathrm{Mg}[\mathrm{NaCl}$, $\mathrm{KCl}, \mathrm{Na}_{2} \mathrm{HPO}_{4}, \mathrm{KH}_{2} \mathrm{PO}_{4}, \mathrm{NaHCO}_{3}$ (Sigma Aldrich, Germany), glucose (Sigma Aldrich, Germany), and $\mathrm{dsdH}_{2} \mathrm{O}$ ] with $\mathrm{pH} 7.4$ and Autoclaved, Ficoll-Hypaque $\quad 10.77$ (Baharafshan, B.I.R.D, Iran).

Neutrophil isolation. Neutrophils were purified from venous blood treated with ACD from healthy volunteers by 3-steps: Dextran sedimentation, Hypotonic lysis, and Ficol sedimetntation (43). Briefly, solution of $6 \%$
Dextran \& $0.9 \% \mathrm{NaCl}$ added into the mixture of ACD \& blood and after adequate mixing, it stood down at room temperature until separation was complete. Then, the yellowish supernatant was separated and centrifuged using a low brake. After breaking the pellet with discarding the supernatant and resuspension in $\mathrm{dsdH}_{2} \mathrm{O}$ at $20 \mathrm{~s}$, it mixed with $0.6 \mathrm{M} \mathrm{KCl}$ and the solution diluted with PBS. Then, it centrifuged using a high brake. The supernatant discarded and the pellet resuspended in PBS. The cell suspension layered over Ficoll-Hypaque and centrifuged using a low brake. Final, the supernatant discarded and the neutrophils pellet resuspended in HBSS. Trypan Blue Viability Test using hemocytometer chamber was performed to assay cell viability and it was $\geq 96 \%$.

Apoptosis assessment. Apoptotic cell death was assessed using FITC-conjugated Annexin-V/PI assay kit (BioVision, USA) by flow cytometry (COULTER, EPICS XLMCL, by Beckman Coulter, USA). Briefly, after collection of $5 \times 10^{5}$ cells by centrifugation, it re-suspended in $500 \mu$ l of $1 \mathrm{X}$ Binding Buffer; then, $5 \mu \mathrm{l}$ of Annexin V-FITC and PI added to suspension; and it 
incubated at room temperature for $5 \mathrm{~min}$ in the dark. Finally, Annexin V-FITC binding analyzed by flow cytometry $(\mathrm{Ex}=488 \mathrm{~nm}$; $\mathrm{Em}=530 \mathrm{~nm}$ ) using FITC signal detector (usually FL1) and PI staining by the phycoerythrin emission signal detector (usually FL2). The percentage of cells stained with Annexin-V only was estimated as early apoptosis; the percentage of cells stained with both Annexin-V and propidium iodide was estimated as late apoptosis or necrotic phase.

Statistical analysis. Repeated measure (two-way) ANOVA was used to determine the effects of TIME and SOLUTION by SPSS software at a significance level of $p=$
0.05. All data were presented as means with standard error of mean.

\section{RESULTS}

Neutrophil Counts. Mauchly's test of sphericity for Neutrophil Counts is met (Mauchly's W $=0.99, \mathrm{p}=0.97$ ). The main effect of TIME with assumption of sphericity was significant $(\mathrm{F}=45.405, \mathrm{p}=$ $0.001)$ and this effect was linear $(F=84.9, p$ $=0.001)$. But, the main effect of SOLUTION wasn't significant $(\mathrm{F}=0.018, \mathrm{p}$ $=0.9)$; besides, the interaction of TIME and SOLUTION with assumption of sphericity was significant $(\mathrm{F}=5.6, \mathrm{p}=0.01)$ and this effect was quadratic $(\mathrm{F}=10.015, \mathrm{p}=0.008)$ [Graph 1].

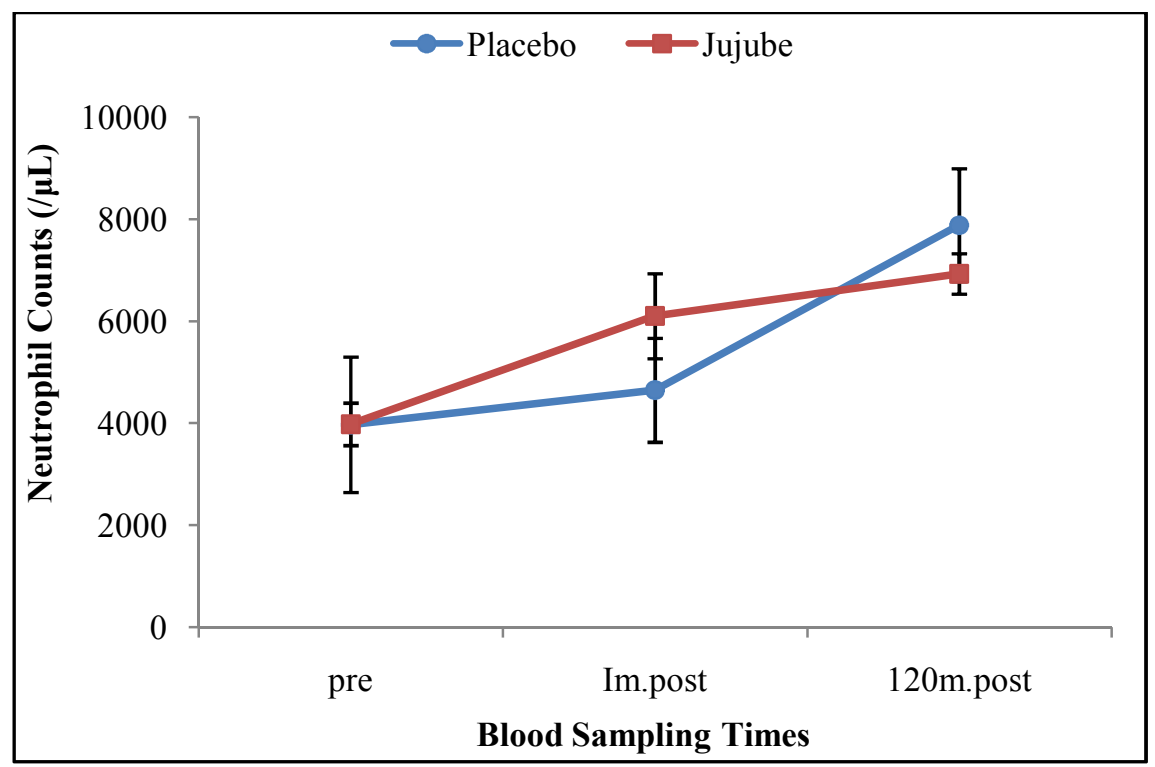

Graph 1. Neutrophil Counts in Response to Short-term Effect of Solution Feeding.

Alive Neutrophils: Mauchly's test of sphericity for Alive Cells is met (Mauchly's $\mathrm{W}=0.67, \mathrm{p}=0.109$ ). The main effect of TIME with assumption of sphericity was significant $(\mathrm{F}=11.92, \mathrm{p}=0.001)$ and this effect was quadratic $(F=15.8, p=0.002)$.
But, the main effect of SOLUTION wasn't significant $(F=0.01, p=0.929)$; besides, the interaction of TIME and SOLUTION with assumption of sphericity was significant $(\mathrm{F}=$ $3.56, \mathrm{p}=0.048)$ and this effect was linear $(\mathrm{F}$ $=4.95, \mathrm{p}=0.049)$ [Graph 2]. 


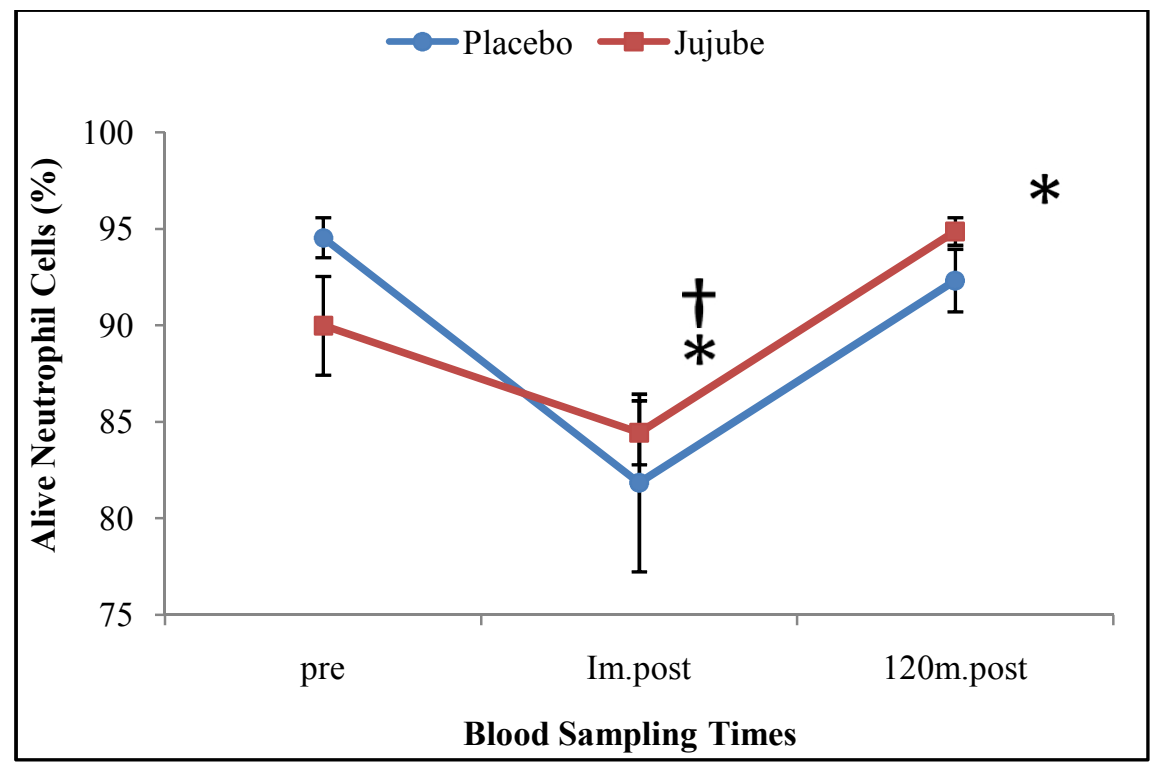

Graph 2. Alive Cell in Response to Short-term Effect of Solution Feeding.

Early Apoptotic Neutrophils: Mauchly's test of sphericity for Early Apoptotic Cells was met (Mauchly's W $=0.89, \mathrm{p}=0.52$ ). The main effect of TIME with assumption of sphericity was significant $(\mathrm{F}=24.72, \mathrm{p}=$ $0.001)$ and this effect was quadratic $(\mathrm{F}=$ 64.1, $\mathrm{p}=0.001)$. Also, the main effect of
SOLUTION was significant $(\mathrm{F}=4.81, \mathrm{p}=$ 0.049 ); besides, the interaction of TIME and SOLUTION with assumption of sphericity was significant $(\mathrm{F}=3.91, \mathrm{p}=0.049)$ and this effect was linear $(F=5.002, p=0.045)$ [Graph 3].

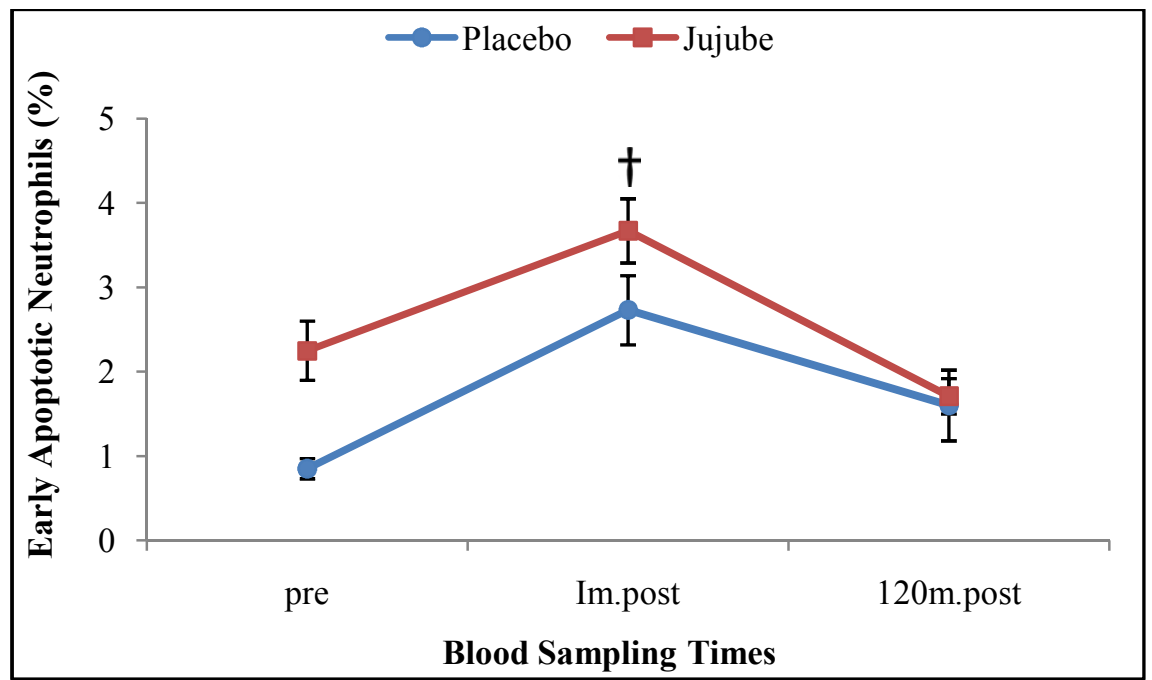

Graph 3. Early Apoptotic Cells in Response to Short-term Effect of Solution Feeding.

Late Apoptotic/Necrotic Neutrophils: Mauchly's test of sphericity for Late
Apoptotic Cells is met (Mauchly's W $=0.64$, $\mathrm{p}=0.08)$. The main effect of TIME with 
assumption of sphericity was significant $(\mathrm{F}=$ $9.29, \mathrm{p}=0.001)$ and this effect was quadratic $(\mathrm{F}=11.82, \mathrm{p}=0.005)$. But, the main effect of SOLUTION wasn't significant $(F=0.4, p$ $=0.54)$; besides, the interaction of TIME and
SOLUTION with assumption of sphericity was significant $(\mathrm{F}=3.55, \mathrm{p}=0.048)$ and this effect was linear $(F=5.07, p=0.049)$ [Graph 4].

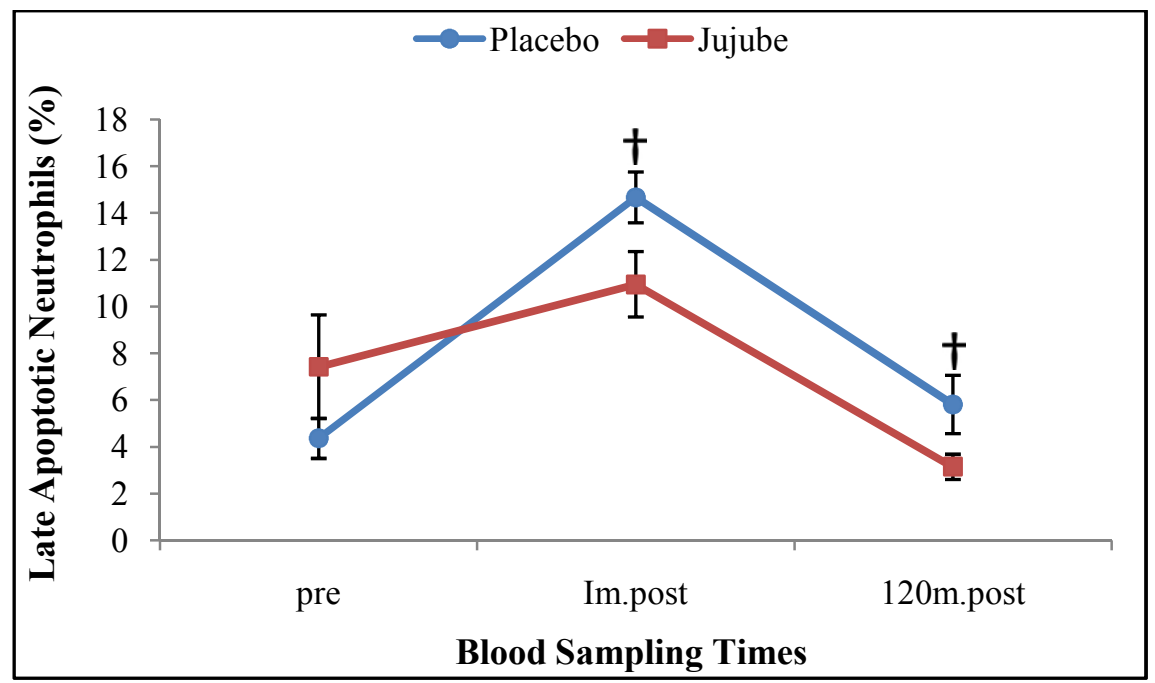

Graph 4. Late Apoptotic Cells in Response to Acute Effect of Solution Feeding.

\section{DISCUSSION}

We saw that Neutrophil Counts increased significantly in response to circuit resistance exercise in both groups of Jujube Solution and Placebo. Many studies have shown that brief exercise increases the circulating neutrophil count $(44,45)$. Ghanbari-Niaki and Tayebi (2013) reported that circulating neutrophil counts of male college students didn't change significantly in response to a single circuit resistance exercise with $35 \%$ 1RM (46); but, Tayebi et al. (unpublished data) showed that a single circuit resistance exercise with $60 \%$ 1RM resulted a significant elevation in circulating neutrophil counts of male college students but not in young male weightlifters.

During very high intensity exercise lasting only 60 seconds the circulating granulocyte count increases and peaks 15 minutes post-exercise (47). It has also been highlighted that for brief exercise the granulocytosis is dependent on intensity (48). The circulating neutrophil count has been reported to increase by up to about 90\% (49) after brief exhaustive exercise. It appears that the demargination of neutrophils by adrenaline is selective, because adrenaline infusion produces a neutrophilia that has a slightly higher percentage of segmented (mature) neutrophils (50), as we saw that Alive Cells increased significantly in placebo group.

Besides, the results of this study showed that Neutrophil Counts of placebo group decreased significantly 120 min after exercise rather than immediately after exercise and also was higher than pre-test. Some studies have demonstrated that only the number of lymphocytes and not neutrophils declined below the corresponding pre-exercise value 2 hours after physical activity (51), as we saw (under review data) an elevation in neutrophil counts after 2 hours of recovery from 1 bout eccentric exercise (only extension from curl up, 80\% 1RM, 8-10 repeats, 6 sets). Recent studies suggest that the decline in leukocyte 
number after exercise occurs due to the induction of leukocyte death (11). Moreover, the increase in DNA fragmentation depends on the intensity and duration of the exercise $(19,52)$. Exhaustive exercise increases DNA fragmentation in the lymphocytes and neutrophils of athletes (53-56). The study of Lagranha et al. (2004) showed an increase in the apoptosis of neutrophils obtained from immature and mature rats after a single session of exercise (21). Similar results were found by Levada-Pires et al. (2008) in neutrophils from elite athletes after competing in a triathlon (54).

Exercise mobilizes peripheral immune cells and the magnitude of this effect reflects the intensity and duration of the effort (57, 58). Intense training increases the susceptibility to infections (59) and this may result from impairment in neutrophil function or acceleration in the process of neutrophil death (11). Short-term exhaustive exercise or intensive treadmill exercise is known to induce DNA damage in lymphocytes in untrained individuals (60). Recently, Lagranha et al. (2004 and 2005) have demonstrated that a single session of exercise induces DNA fragmentation and mitochondrial membrane depolarization, increases expression of pro-apoptotic genes (bax and bcl-xS) and decreases expression of anti-apoptotic genes (bcl-xL) in rat neutrophils. $(19,21)$

Apoptosis is a very complex phenomenon involving a regulated series of events, in part controlled by extracellular stimuli including cytokines and perhaps nutrient availability (61).

However the role of glucose and glutamine for apoptosis process remains poorly understood; but some studies mentioned that neutrophils utilize these metabolites at high rates (62).

Previous studies have revealed that jujube contains various constituents, including triterpenic acids, flavonoids, cerebrosides, amino acids, phenolic acids, mineral constituents, and polysaccharides and phytochemical studies of jujube fruits have shed some light on their biological effects, such as the anticancer, anti-inflammatory, anti-obesity, immune-stimulating, antioxidant, hepato-protective, and gastrointestinal protective activities and inhibition of foam cell formation in macrophages (63).

Our results showed that since neutrophil counts of jujube solution group increased during exercise, in placebo group didn't have any change. But neutrophil counts of placebo group elevated during recovery as it suppressed in jujube solution group (interaction effect of time and solution). Besides, since living neutrophils of placebo group decreased significantly during exercise, it decreased insignificantly in jujube solution group, in other words, it suppressed. But living neutrophils of placebo group increased to baseline during recovery, so that of jujube solution group increased above baseline. On the other side, early apoptotic neutrophils of jujube solution group had a significant increase less than significant increase of placebo group, and also during recovery, it decreased to under baseline in jujube solution group, but it didn't change in placebo group. Also, since late apoptotic neutrophils of jujube solution group suppressed during exercise and elevated in placebo group more than it. Although both groups had a significant decrease to baseline during recovery, it went under baseline in jujube solution group.

It is not clear that pretreated with oral Ziziphus Jujube solution in our research condition suppressed neutrophil apoptosis by what mechanism. Nonetheless, with respect to medicinal and effective composition container in jujube zizifus, it can be mentioned to some likely mechanisms of immune effect of jujube zizifus. Current researches about Ziziphus Jujube fruit show that its extraction have cytotoxic activity and can induce apoptosis in cancer cells and 
some tumor cells (40). They suggested that infusion of Ziziphus Jujube extraction to cultured cells caused shrinkage, and detachment of adhesive cells, HeLa and HEp-2. These effects increased by adding to extraction levels. Besides, it is noticed the anti-proliferative and tumor cell growth inhibitory effect of triterpene acids fraction container Ziziphus Jujube. It is maybe because of pretreated with Ziziphus Jujube solution could be prevented from that activity of neutrophils against physical stress. Huang et al. (2007) evaluated the effect of a Chinese mixture medicine container Ziziphus Jujube as immune stimulus of mice. The results showed that the mixture could prevent from decrease of white blood cell count caused by cyclophosphamide (cyclophosphamideinduced leucopenia) (64). Shen et al. (2009) observed that treating of mice with ethanol extraction of Ziziphus Jujube in two dosages of 100 and $200 \mathrm{~mL} / \mathrm{kg}$ of body weight could prevent from decreasing activity of antioxidant levels (glutathione and superoxide dismutase) caused by carbon tetrachloride (ccl4-induced) (37). Ganachari, Kumar, and Bhat (2004) studied the effect of Ziziphus jujuba leaves extract on phagocytosis by human neutrophils and saw that the extract elevated motion of neutrophils from up section to under of filter as dose-related and decreased neutrophilic phagocytosis gently with increase of extract level (65). Yu et al. (2012) and Goyal et al. (2011) investigated the anti-inflammatory effects of Ziziphus jujube; and demonstrated that the triterpene acids fraction was the most active part of jujube through the inhibitory effects on the inflammatory cells activated by Euphorbia kansui and prostratin, a phorbol ester isolated from Euphorbia fischeriana (66); or suggested that it plays a protective role against experimental acute and chronic inflammatory reactions in rat, possibly by attenuating NOS activity (67). Also, Li et al.
(2011) and Zhao et al. (2006) studied the immune stimulus effects of Ziziphus jujube; and reported that its polysaccharides fractions (ZSP) such as crude ZSP dramatically increased thymus and spleen indices in mice and enhanced the proliferation of splenocytes and peritoneal macrophages (68); and/or its pectic polysaccharides (Ju-B-2) had a significant activity in enhancing the effect of spleen cells proliferation at a higher dose $(>30$ $\mu \mathrm{g} / \mathrm{mL}$ ) (69). But, about its immunological effect in exercise and training doesn't exist in any evidence. Only, Ghanbari-Niaki et al. (2013) studied the effect of aerobic training with and without Zizyphus Jujuba water extraction on liver and plasma Nesfatin-1 (27) and fundus Nesfatin-1, ATP, HDL-C, and LDL-C concentrations (26) of female rats and reported that exercise training with Zizyphus Jujuba water extraction probably prevent from overweighting and cardiovascular disease (26) and it could be considered as an anti-appetite herb (27). Tayebi et al. (unpublished data) investigated acute effects of oral feeding Jujube Ziziphus solution an hour before a single session of circuit resistance exercise (exactly such as this study protocol) on apoptosis of human neutrophil and observed that neutrophil apoptosis suppressed in Jujube Ziziphus solution.

According to nutrition sciences, jujuba consists of different nutrient and materials including sugars (Starch 21.8\%, fructose $16 \%$, glucose $9.6 \%$, and sucrose $21.8 \%$ ), Fat (19\%), various amino acids (Glycine, histidine, leucine, iso-leucine, phenylalanine, proline, serine, threonine and etc.), glutamic acid, protein (4.5-5.6\%), various minerals (Iron, sodium, potassium, zinc, manganese, sulfur and etc.) and vitamins (C, B1, B). Generally, jujube fruit is high in carbohydrates, especially fructose and glucose, which account for about $77 \%$ of its weight. Vitamins $\mathrm{C}, \mathrm{B}$ complex, and $\mathrm{A}$, as well as calcium, potassium, and other 
mineral elements, have also been identified in jujuba fruit $(70,71)$.

As it was mentioned in the previous studies, glucose and glutamine are two of the most important fuel for the cell of immune system. The functionality of glutamine in rats' neutrophils was particularly studied, and it was proven for the first time that the extent of glutamine consumption in these cells was higher than glucose (62). It seems that glutamine consumption has increased in apoptosis neutrophils. On the other hand, it has been indicated that glutamine postponed the occurrence of spontaneous apoptosis in neutrophils, and plasma concentration of glutamine was always positively correlated to MTP (22). A decline in MTP was detected as the necessary commitment of cells to apoptosis (55). Also, glutamine plasma was inversely externalized with annexin $\mathrm{V}$ binding to phosphatidylserine, and it was correlated with chromatin concentration of neutrophils in both rats and humans (22).

On the other hand, amino acids such as alanin, aspartic acid, especially glutamic acid can participate in synthesis of glutamine, and it seems that availability of these amino acids in body by its loading a week before exercise can be effective in glutamine synthesis. So it can be concluded that apoptosis suppression in Jujube Ziziphus group is because of glucose and glutamine availability resulted from loading of amino acids during a week before examination.

\section{CONCLUSION}

In conclusion, it is considered that this study examine the effects of supplementation with water solution of Jujube Ziziphus on apoptotic situation caused by exercise and antiapoptotic effect of it with resistance exercise for the first time. The results suggest that oral Jujube Ziziphus solution can be a proper supplement before resistance activities specially circuit resistance exercise because of its nutritional characteristics and values, because it can prevent from elevation of neutrophil apoptosis caused by circuit resistance exercise as it is related to occurrence of some intracellular events. Therefore, it is needed to conduct more researches to clarify proper mechanisms of inhibitory and anti-apoptotic effects of Jujube Ziziphus.

\section{REFFRENCES}

1. Brinkmann V, Reichard U, Goosmann C, Fauler B, Uhlemann Y, Weiss DS, et al. Neutrophil Extracellular Traps Kill Bacteria. Science. 2004;303(5663):1532-5.

2. Duffin R, Leitch AE, Fox S, Haslett C, Rossi AG. Targeting granulocyte apoptosis: mechanisms, models, and therapies. Immunological reviews. 2010;236:28-40. Epub 2010/07/20.

3. Pillay J, den Braber I, Vrisekoop N, Kwast LM, de Boer RJ, Borghans JAM, et al. In vivo labeling with $2 \mathrm{H} 2 \mathrm{O}$ reveals a human neutrophil lifespan of 5.4 days. Blood. 2010;116(4):625-7.

4. Serhan CN, Brain SD, Buckley CD, Gilroy DW, Haslett C, O'Neill LA, et al. Resolution of inflammation: state of the art, definitions and terms. FASEB journal : official publication of the Federation of American Societies for Experimental Biology. 2007;21(2):325-32. Epub 2007/02/03.

5. Raza K, Scheel-Toellner D, Lee CY, Pilling D, Curnow SJ, Falciani F, et al. Synovial fluid leukocyte apoptosis is inhibited in patients with very early rheumatoid arthritis. Arthritis research \& therapy. 2006;8(4):R120. Epub 2006/07/25.

6. Fialkow L, Fochesatto Filho L, Bozzetti MC, Milani AR, Rodrigues Filho EM, Ladniuk RM, et al. Neutrophil apoptosis: a marker of disease severity in sepsis and sepsis-induced acute respiratory distress syndrome. Critical care (London, England). 2006;10(6):R155. Epub 2006/11/10.

7. Munoz LE, Lauber K, Schiller M, Manfredi AA, Herrmann M. The role of defective clearance of apoptotic cells in systemic autoimmunity. Nature reviews Rheumatology. 2010;6(5):280-9. Epub 2010/05/01.

8. Fitzpatrick AM, Holguin F, Teague WG, Brown LA. Alveolar macrophage phagocytosis is impaired in children with poorly controlled asthma. The Journal of allergy and clinical immunology. 2008;121(6):1372-8, 8 e1-3. Epub 2008/04/18. 
9. Mooren FC, Völker K, Klocke R, Nikol S, Waltenberger J, Krüger K. Exercise delays neutrophil apoptosis by a G-CSF-dependent mechanism. Journal of Applied Physiology. 2012;113(7):1082-90.

10. Tuan TC, Hsu TG, Fong MC, Hsu CF, Tsai KKC, Lee CY, et al. Deleterious effects of short-term, high-intensity exercise on immune function: evidence from leucocyte mitochondrial alterations and apoptosis. British Journal of Sports Medicine. 2008;42(1):11-5.

11. Hsu T-G, Hsu K-M, Kong C-W, Lu F-J, Cheng HU, Tsai K. Leukocyte mitochondria alterations after aerobic exercise in trained human subjects. Medicine \& Science in Sports \& Exercise. 2002;34(3):438-42.

12. Syu GD, Chen HI, Jen CJ. Severe Exercise and Exercise Training Exert Opposite Effects on Human Neutrophil Apoptosis via Altering the Redox Status. PLoS One. 2011;6(9):e24385. Epub 2011/09/21.

13. Beavers KM, Brinkley TE, Nicklas BJ. Effect of exercise training on chronic inflammation. Clinica chimica acta; international journal of clinical chemistry. 2010;411(11-12):785-93. Epub 2010/03/02.

14. Geering B, Simon HU. Peculiarities of cell death mechanisms in neutrophils. Cell Death Differ. 2011;18(9):1457-69.

15. Savill JS, Wyllie AH, Henson JE, Walport MJ, Henson PM, Haslett C. Macrophage phagocytosis of aging neutrophils in inflammation. Programmed cell death in the neutrophil leads to its recognition by macrophages. The Journal of clinical investigation. 1989;83(3):865-75. Epub 1989/03/01.

16. Gleeson M. Can Nutrition Limit Exercise-Induced Immunodepression? Nutrition Reviews. 2006;64(3):119-31.

17. Gleeson M, Nieman DC, Pedersen BK. Exercise, nutrition and immune function. Journal of sports sciences. 2004;22(1):115-25.

18. Walsh NP, Blannin AK, Bishop NC, Robson PJ, Gleeson M. Effect of oral glutamine supplementation on human neutrophil lipopolysaccharide-stimulated degranulation following prolonged exercise. Int J Sport Nutr Exerc Metab. 2000;10(1):39-50.

19. Lagranha CJ, deLima TM, Senna SM, Doi SQ, Curi R, Pithon-Curi TC. The effect of glutamine supplementation on the function of neutrophils from exercised rats. Cell Biochemistry and Function. 2005;23(2):101-7.

20. Lagranha CJ, Hirabara SM, Curi R, Pithon-Curi TC. Glutamine supplementation prevents exercise-induced neutrophil apoptosis and reduces p38 MAPK and JNK phosphorylation and p53 and caspase 3 expression. Cell Biochem Funct. 2007;25(5):563-9. Epub 2007/06/02.

21. Lagranha CJ, Senna SM, De Lima TM, Silva ÉPP, Doi SQ, Curi RUI, et al. Beneficial Effect of Glutamine on Exercise-Induced Apoptosis of Rat Neutrophils. Medicine and science in sports and exercise. 2004;36(2):210-7.

22. Pithon-Curi TC, Schumacher RI, Freitas JJ, Lagranha C, Newsholme P, Palanch AC, et al. Glutamine delays spontaneous apoptosis in neutrophils. Am J Physiol Cell Physiol. 2003;284(6):C1355-61. Epub 2003/01/17.

23. Solati J, Soleimani N. Antihyperglycemic and antihyperlipidemic effects of Ziziphus vulgaris L. on streptozocininduced [corrected] diabetic adult male Wistar rats. Acta diabetologica. 2010;47 Suppl 1:219-23. Epub 2009/12/05.

24. Tian WX, Li LC, Wu XD, Chen CC. Weight reduction by Chinese medicinal herbs may be related to inhibition of fatty acid synthase. Life sciences. 2004;74(19):2389-99. Epub 2004/03/05.

25. Osman MA, Ahmed MA. Chemical and proximate composition of (Zizyphus spina-christi) nabag fruit. Nutrition \& Food Science. 2009;39(1):70-5.

26. Ghanbari Niaki A, Hosseini F, Rooadbari F, Rahmati Ahmadabad S, Rooadbari M. Effects of Aerobic Training, with or without Zizyphus Jujuba Water Extraction, on Fundus Nesfatin-1, ATP, HDL-C, and LDL-C Concentrations in Female Rats. Iranian Journal of Health and Physical Activity. 2013;4(1):9-16.

27. Ghanbari Niaki A, Mohammadi Joojadeh F, Zare Kookandeh N, Najafi S, Chaichi MJ, Rodbari F, et al. Liver and Plasma Nesfatin-1 Responses to 6 Weeks of Treadmill Running With or Without Zizyphus Jujuba Liquid Extraction in Female Rat. Int J Endocrinol Metab. 2013;11(2):95-101.

28. Bown D, Herb Society of A. Encyclopedia of herbs and their uses: Dorling Kindersley; 1995. 424 p.

29. Duke JA, Ayensu ES. Medicinal plants of China: Reference Publications Algonac; 1985. S219-S24 p.

30. Him-Che Y. Handbook of Chinese herbs and formulas. Institute of Chinese Medicine, Los Angeles. 1985;1:S219-S24.

31. Jiang C, Luyi W, Lan W. The Effect of Injection Fluid of Jujube on the Immune Function of Mice [J]. Journal of Baotou Medical College. 2002;2:[Article in Chinese, Abstract in English[

32. Li X, Yin J, Zou J. Effect of compound jujube oral liquid on immune function of mouse. China Tropical Medicine. 2009;8:[Article in Chinese, Abstract in English[

33. Renbang YHZWZ, Liqiang LWX. Effects on Immune Function of Gold Thread Jujube Syrup in Mice. Journal of Chinese Institute of Food Science and Technology. 2008; 1:[Article in Chinese, Abstract in English[

34. Shi L, Zhang Z. Effect of compound Jujube oral liquid on immune function of rats. Journal of Jilin Military Medical College Fourth Military Medical University. 2005;1:[Article in Chinese, Abstract in English[

Tayebi, S. M., et al. (2014). Ann Appl Sport Sci, 2(1): 53-68. 
35. Zhonghua W, Xiuqi H, Quanhai G. Effects of jujube oligosaccharides on production performance and immune function of laying chicken. China Feed. 2011;19:[Article in Chinese, Abstract in English[

36. Chen CF, Lee JF, Wang D, Shen CY, Shen KL, Lin MH. Water extract of Zizyphus Jujube attenuates ischemia/reperfusion-induced liver injury in rats (PP106). Transplantation proceedings. 2010;42(3):741-3. Epub 2010/05/01.

37. Shen X, Tang Y, Yang R, Yu L, Fang T, Duan JA. The protective effect of Zizyphus jujube fruit on carbon tetrachloride-induced hepatic injury in mice by anti-oxidative activities. J Ethnopharmacol. 2009;122(3):555-60.

38. Zhang H, Jiang L, Ye S, Ye Y, Ren F. Systematic evaluation of antioxidant capacities of the ethanolic extract of different tissues of jujube (Ziziphus jujuba Mill.) from China. Food and chemical toxicology : an international journal published for the British Industrial Biological Research Association. 2010;48(6):1461-5. Epub 2010/03/17.

39. Sun Y-F, Song C-K, Viernstein H, Unger F, Liang Z-S. Apoptosis of human breast cancer cells induced by microencapsulated betulinic acid from sour jujube fruits through the mitochondria transduction pathway. Food Chemistry. 2013;138(2-3):1998-2007.

40. Vahedi F, Fathi Najafi M, Bozari K. Evaluation of inhibitory effect and apoptosis induction of Zyzyphus Jujube on tumor cell lines, an in vitro preliminary study. Cytotechnology. 2008;56(2):105-11. Epub 2008/11/13.

41. Liang S, Juan J. Effect of jujube extract on oxidative injury in heart muscles of exhausted training rats. African Journal of Microbiology Research. 2011;5(14):1896-9.

42. Ghanbari-Niaki A. Ghrelin and glucoregulatory hormone responses to a single circuit resistance exercise in male college students. Clinical Biochemistry. 2006;39(10):966-70.

43. Heit BJ. Human Peripheral blood's Neutrophil isolation. 2001 [cited 2012]; Available from: http://www.bio.net/bionet/mm/immuno/2001-August/016695.html.

44. McCarthy DA, Dale MM. The leucocytosis of exercise. A review and model. Sports medicine (Auckland, NZ). 1988;6(6):333-63. Epub 1988/12/01.

45. Pyne DB. Regulation of neutrophil function during exercise. Sports medicine (Auckland, NZ). 1994;17(4):24558. Epub 1994/04/01.

46. Ghanbari-Niaki A, Tayebi SM. Effects of a Light Circuit Resistance Exercise Session on Some Hematological Parameters of Male Collage Students. Annals of Applied Sport Science. 2013;1(1):6-11.

47. Gabriel H, Urhausen A, Kindermann W. Mobilization of circulating leucocyte and lymphocyte subpopulations during and after short, anaerobic exercise. European journal of applied physiology and occupational physiology. 1992;65(2):164-70. Epub 1992/01/01.

48. Gabriel H, Schwarz L, Steffens G, Kindermann W. Immunoregulatory hormones, circulating leucocyte and lymphocyte subpopulations before and after endurance exercise of different intensities. International journal of sports medicine. 1992;13(5):359-66. Epub 1992/07/01.

49. Field CJ, Gougeon R, Marliss EB. Circulating mononuclear cell numbers and function during intense exercise and recovery. J Appl Physiol. 1991;71(3):1089-97. Epub 1991/09/01.

50. Fehr J, Grossmann HC. Disparity between circulating and marginated neutrophils: evidence from studies on the granulocyte alkaline phosphatase, a marker of cell maturity. American journal of hematology. 1979;7(4):369-79. Epub 1979/01/01.

51. Krzywkowski K, Petersen EW, Ostrowski K, Kristensen JH, Boza J, Pedersen BK. Effect of glutamine supplementation on exercise-induced changes in lymphocyte function. Am J Physiol Cell Physiol. 2001;281(4):C1259-65. Epub 2001/09/08.

52. Levada-Pires AC, Cury-Boaventura MF, Gorjao R, Hirabara SM, Puggina EF, Pellegrinotti IL, et al. Induction of lymphocyte death by short- and long-duration triathlon competitions. Medicine and science in sports and exercise. 2009;41(10):1896-901. Epub 2009/09/04.

53. Hartmann A, Plappert U, Raddatz K, Grunert-Fuchs M, Speit G. Does physical activity induce DNA damage? Mutagenesis. 1994;9(3):269-72. Epub 1994/05/01.

54. Levada-Pires AC, Cury-Boaventura MF, Gorjao R, Hirabara SM, Puggina EF, Peres CM, et al. Neutrophil death induced by a triathlon competition in elite athletes. Medicine and science in sports and exercise. 2008;40(8):1447-54. Epub 2008/07/11.

55. Phaneuf S, Leeuwenburgh C. Apoptosis and exercise. Medicine \& Science in Sports \& Exercise. 2001;33(3):3936.

56. Wang JS, Huang YH. Effects of exercise intensity on lymphocyte apoptosis induced by oxidative stress in men. Eur J Appl Physiol. 2005;95(4):290-7. Epub 2005/08/13.

Tayebi, S. M., et al. (2014). Ann Appl Sport Sci, 2(1): 53-68. 
57. Matthews CE, Ockene IS, Freedson PS, Rosal MC, Merriam PA, Hebert JR. Moderate to vigorous physical activity and risk of upper-respiratory tract infection. Medicine and science in sports and exercise. 2002;34(8):1242-8. Epub 2002/08/08.

58. Silveira EM, Rodrigues MF, Krause MS, Vianna DR, Almeida BS, Rossato JS, et al. Acute exercise stimulates macrophage function: possible role of NF-kappaB pathways. Cell Biochem Funct. 2007;25(1):63-73. Epub 2006/08/15.

59. Castell LM, Poortmans JR, Newsholme EA. Does glutamine have a role in reducing infections in athletes? European journal of applied physiology and occupational physiology. 1996;73(5):488-90. Epub 1996/01/01.

60. Mars M, Govender S, Weston A, Naicker V, Chuturgoon A. High Intensity Exercise: A Cause of Lymphocyte Apoptosis? Biochemical and biophysical research communications. 1998;249(2):366-70.

61. Duchen MR. Contributions of mitochondria to animal physiology: from homeostatic sensor to calcium signalling and cell death. The Journal of Physiology. 1999;516(1):1-17.

62. Curi TC, De Melo MP, De Azevedo RB, Zorn TM, Curi R. Glutamine utilization by rat neutrophils: presence of phosphate-dependent glutaminase. The American journal of physiology. 1997;273(4 Pt 1):C1124-9. Epub $1997 / 11 / 14$.

63. Gao Q-H, Wu C-S, Wang M. The Jujube (Ziziphus Jujuba Mill.) Fruit: A Review of Current Knowledge of Fruit Composition and Health Benefits. J Agric Food Chem. 2013;61(14):3351-63.

64. Huang GC, Wu LS, Chen LG, Yang LL, Wang CC. Immuno-enhancement effects of Huang Qi Liu Yi Tang in a murine model of cyclophosphamide-induced leucopenia. J Ethnopharmacol. 2007;109(2):229-35.

65. Ganachari MS, Kumar S, Bhat KG. Effect of Ziziphus jujuba leaves extract on phagocytosis by human neutrophils. Journal of Natural Remedies. 2004;4(1):47-51.

66. Yu L, Jiang BP, Luo D, Shen XC, Guo S, Duan JA, et al. Bioactive components in the fruits of Ziziphus jujuba Mill. against the inflammatory irritant action of Euphorbia plants. Phytomedicine. 2012;19(3-4):239-44.

67. Goyal R, Sharma P, Singh M. Possible attenuation of nitric oxide expression in anti-inflammatory effect of Ziziphus jujuba in rat. J Nat Med. 2011;65(3-4):514-8.

68. Li J, Shan L, Liu Y, Fan L, Ai L. Screening of a functional polysaccharide from Zizyphus Jujuba cv. Jinsixiaozao and its property. International journal of biological macromolecules. 2011;49(3):255-9. Epub 2011/05/05.

69. Zhao Z, Li J, Wu X, Dai H, Gao X, Liu M, et al. Structures and immunological activities of two pectic polysaccharides from the fruits of Ziziphus jujuba Mill. cv. jinsixiaozao Hort. Food Research International. 2006;39(8):917-23.

70. Guil-Guerrero JL, Diaz Delgado A, Matallana Gonzalez MC, Torija Isasa ME. Fatty acids and carotenes in some ber (Ziziphus jujuba Mill) varieties. Plant foods for human nutrition (Dordrecht, Netherlands). 2004;59(1):23-7. Epub 2005/01/29.

71. Huang YL, Yen GC, Sheu F, Chau CF. Effects of water-soluble carbohydrate concentrate from Chinese jujube on different intestinal and fecal indices. J Agric Food Chem. 2008;56(5):1734-9. Epub 2008/02/07.

Tayebi, S. M., et al. (2014). Ann Appl Sport Sci, 2(1): 53-68. 
تازههاى علوم كاربردى ورزش

مقاله اصيل

دوره دوم، شماره اول

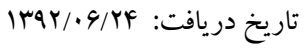

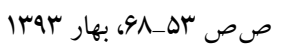

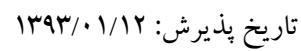

\section{اثر مصرف كوتاهمدت محلول خوراكى عناب قبل از يك جلسه ورزش مقاومتى دايرهاى بر آيويتوز نوتروفيل انسانى}

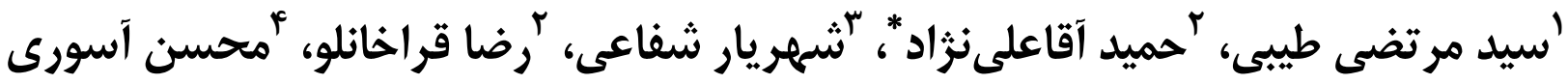

ا. استاديار فيزيولوزى ورزشى دانشكده تربيت بدنى و علوم ورزشى، دانشكاه علامه طباطبايى، تهران، ايران.

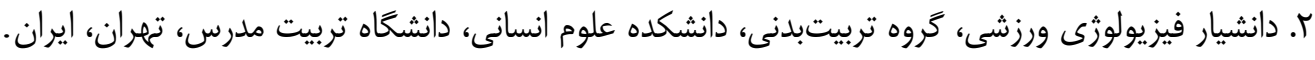

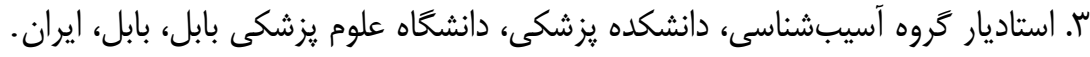
أ. مركز تحقيقات شمال كشور، انستيتو ياستور ايران، آمل، ايران.

קكيده

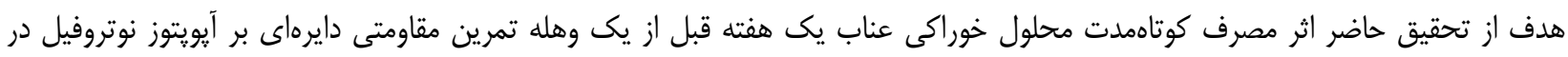

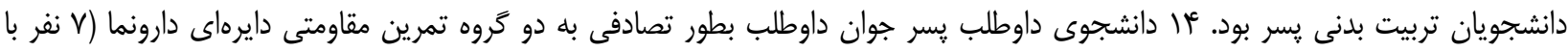

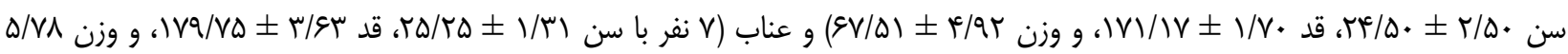

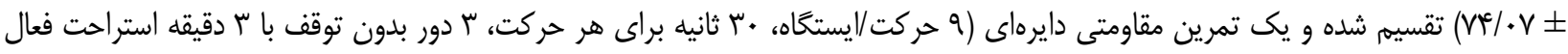

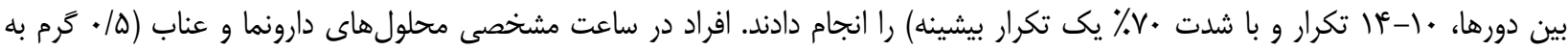

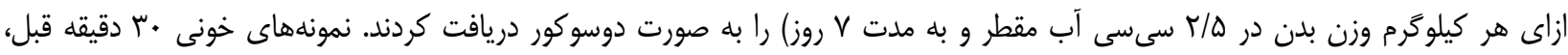

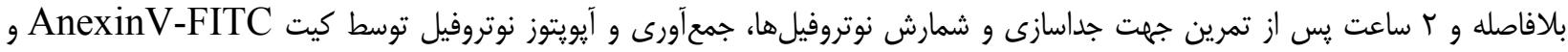

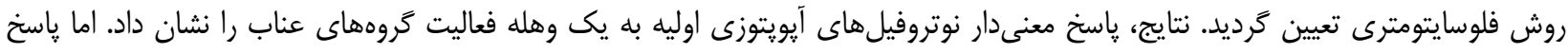

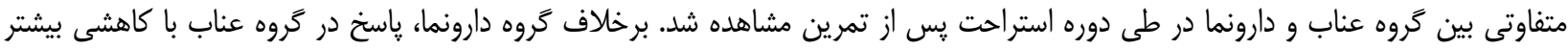

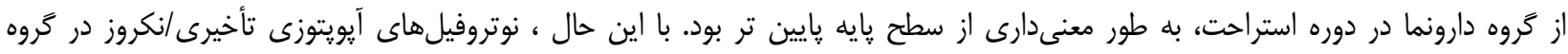

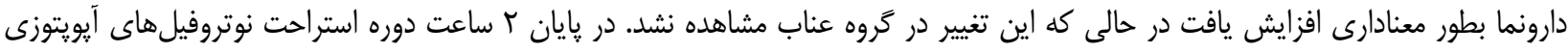

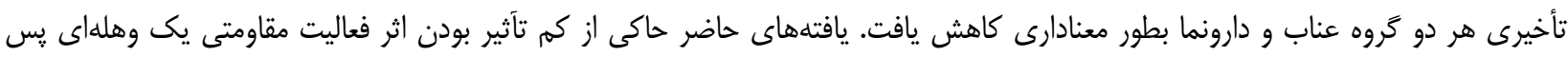

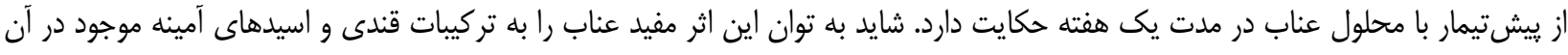

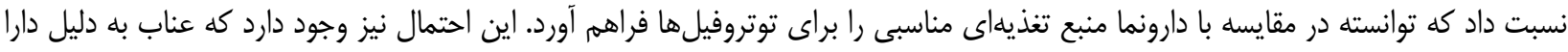

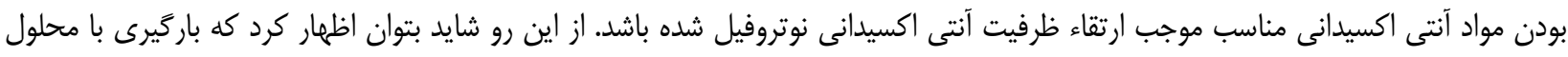

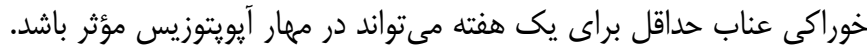

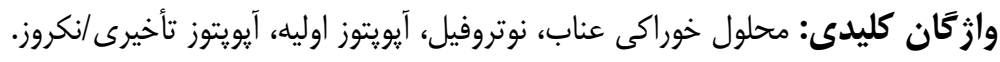


